highly controversial area; indeed, some of the flavour of this controversy is evident in the article, lending it at times an almost polemical tone. Equally clear is the discussion by Damaskin and Kazarimov on the adsorption of organic molecules onto electrodes; from the pedagogical point of view, this is the most successful article in the book.

Frumkin and co-authors present a detailed account of the concept of potential of zero charge. This topic has attracted several recent reviews and a book (by Frumkin); the present article is in fact a reprise of that book and will be welcomed therefore in the West. The importance of the concept of pzc is amply illustrated in the present review and my only criticism is that there remain some problems in notation, both between this article and others in the volume, and indeed between text and figure captions.

The articles by Pleskov, Boguslavsky and Hunter are devoted to various aspects of the non-metal/electrolyte interface. Pleskov's essay reviews the double-layer on classical semiconductors and is an able summary of the famous book by Myamlin and Pleskov (Electrochemistry of Semiconductors; Plenum, 1967), but I was disappointed to find so few references to work of the past decade, especially given the explosion of interest that has occurred in this field. Boguslavsky has provided a welcome if rather tentative account of the insulator/electrolyte interface and Hunter a brief but most useful description of colloids.

The present volume contains some essays of great value; in others the development is rather eclectic and the overall result is somewhat uneven. Nevertheless, the first volume of this series will undoubtedly become a standard work. Nothing quite so detailed has been attempted before in electrochemistry, and firmer editorial control should ensure that subsequent volumes will more than fulfil its promise. $\square$

Andrew Hamnett is University Lecturer in Inorganic Chemistry and Fellow of St Catherine's College, Oxford.

\title{
Population genetics with age - not forgetting the genes
}

\section{Michael Bulmer}

Evolution in Age-Structured Populations. By Brian Charlesworth. Pp.300. (Cambridge University Press: 1980.) Hbk $£ 18, \$ 44.50$; pbk £5.95, \$13.50.

THIS is the first book in a new series called Cambridge Studies in Mathematical Biology, the aim of which is that "each book will be self-contained, covering necessary background theory, but without allowing the mathematical details to obscure biological relevance",. The book under review admirably fulfils these aims.

The classical theory of population genetics assumes a life-history with discrete, non-overlapping generations in which all individuals in the population at a particular time are the same age. This model is appropriate for annual plants and insects, but not for a large number of species (most vertebrates, for example) with overlapping generations. In the latter situation, the population at a particular time consists of individuals of different ages with fecundities and survival probabilities dependent on their age, and a proper theory of its population genetics should take its age structure into account. In particular, it is clearly impossible to consider how natural selection moulds the way in which fecundity and survival depend on age without considering age structure, so that recent interest in the evolution of life-history strategies has stimulated theoreticians to extend classical population genetics theory to include agestructure as a variable. Brian Charlesworth reviews and summarizes this work, much of which is his own.

Five chapters develop the subject in a logical way. The first introduces the relevant demographic theory, and the next discusses population genetics in agestructured populations without selection (Hardy-Weinberg and linkage equilibrium, and genetic drift in finite populations); of particular value is the description of the elegant work of Hajnal on the frequencies of consanguineous matings in an isolated population.

Chapters 3 and 4 form the core of the book and describe the effect of selection in an age-structured population. The author remarks that important work on this subject was published by Haldane and Norton in the late $1920 \mathrm{~s}$, but that further work was inhibited by the introduction by Fisher of his "Malthusian parameter" method in 1930, which apparently provided a simple and elegant answer to the problem. However, it has been recognized in the past ten years that this method is defective because a particular genotype cannot have a fixed Malthusian parameter when the genotypic composition of the population is changing under selection; there is no short-cut to the methodology introduced by Haldane and Norton.

Finally, Charlesworth discusses the evolution of life-history strategies, that is to say the evolution of senescence and of reproductive patterns. This is the most interesting area of application of the ideas developed in the book; the author's general conclusion is that

although qualitative agreement between theoretical expectation and observed differences in life-histories between and within species is often good, no studies of natural populations have really been capable of demonstrating close quantitative agreement between a real and an optimal life-history.

Few would disagree with this comment.

This is an important book which can be recommended to anyone with an interest in population genetics and evolutionary biology. The argument is presented clearly from first principles; the author does not belong to the hand-waving school of thought which believes that, when the going gets difficult, it is possible to do population genetics without genes. The mathematical level is reasonably straightforward, but it is at times difficult to see the wood for the trees; a reader might do well to make a rapid first reading before studying the details.

Incidentally, it should be noted that Bernardelli is throughout mis-spelt "Bernadelli"; this is probably a copying error from a secondary source - a classical deletion mutation.

Michael Bulmer is a Lecturer in Biomathematics at Oxford University.

\section{SCIENTIFIC BOOKSHOP}

H.K. LEWIS can supply works in all branches of Pure and Applied Science. Catalogues on request. Please state interests.

\section{SCIENTIFIC LENDING LIBRARY}

Annual Subscription from $\mathbf{6 7 . 5 0}$. (Available in U.K. only)

Reduced rates for multiple subscriptions.

Prospectus post free on request.

Quarterly List of New Books and new editions added to the Library sent post free to subscribers regularly.

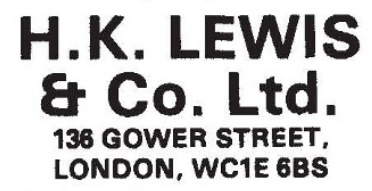

Telephone: 01-387 4282

Telegrams: "Publicavit,

London, WCiE 6BS." 